\title{
Local Economic Development Initiatives in Ghana: The Challenges and the Way Forward
}

\author{
James Kwame Mensah \\ University of Ghana Business School \\ Department of Public Administration and Health Services Management \\ Email: mensjam@gmail.com \\ Justice Nyigmah Bawole \\ University of Ghana Business School \\ Department of Public Administration and Health Services Management \\ Email: jnbawole@ug.edu.gh
}

Albert Ahenkan (Corresponding author)

University of Ghana Business School

Department of Public Administration and Health Services Management

Email: aahenkan@ug.edu.gh

Received: May 30, 2013 Accepted: June 15, 2013 DOI: 10.5296/jpag.v3i2.3781

\begin{abstract}
This case study presents and analyses Local Economic Development (LED) initiatives and challenges from two districts in Ghana. The study is a qualitative case study that uses individual interviews through purposive selection from officials who are directly involved in the formulation and implementation of district development initiatives. The study found that the district does not have a LED policy in place but have initiated and implemented a number of programmes that are pro-LED. These programmes are in the area of agriculture, human resource development, financing and infrastructure development. However, the implementation of these initiatives has encountered many challenges such as inadequate human resource, finance, absence of LED policy and improper collaboration among local level actors. The paper provides the way forward for the initiation and implementation of LED at the local level.
\end{abstract}

Keywords: Local Economic Development, Implementation, Challenges 


\section{Introduction}

In the quest to achieve national development goals, there is an increasing recognition that this could only happen when the goals are translated into actions at the sub-national levels and by active involvement of local actors. This in turn brought about renewed attention to planning for local economic development, which is output and impact oriented and linked to the national level policies and budget processes. Local Economic Development (LED) is a bottom up approach to economic growth through the realization of the economic potentials of every territory. The crux of LED is that every territory has comparative advantage which can be enhanced if the necessary actions are taken to tackle the bottlenecks inhibiting their success. These can be done through a partnership between the public, private and civil society sectors who all contribute differently to the promotion of LED.

Although LED as a concept dates back to the 1960s and 1970s, it was not until the late 1990s that an emphasis on enterprise development, improving infrastructure, building local partnerships, and generally promoting an inclusive and dynamic framework became the dominant strategy (World Bank, 2003). To Davis and Catherine (2005), many factors have generated the change in direction and perhaps the rise in income disparities and inequalities between large cities and less urban areas are crucial among these factors.

Concerning the role of LED, Adebayo and Taibat (2006) state that the role of LED within a community includes, setting up, running and supporting an endogenous network that is able to catalyse development. They further state that, the essential mission of LED is to create jobs, promote and support small and medium-sized enterprises, improve the economic context and opportunity of the territory, and use businesses as a weapon in the fight against poverty. To add to the above, LED initiatives include: ensuring the functionality of local investment climate in order to boost local businesses, the encouragement of new enterprise, attracting outside investments, and investing in physical infrastructure. Human resource development and institutional support systems, supporting the growth of particular clusters of businesses, targeting certain disadvantaged groups and particular parts of the city for regeneration and supporting survivalist businesses should not be left out in the LED strategy (Pieterse, 2006).

In Ghana, LED is carried out by the District Assemblies (DAs) which have been mandated by the constitution to pursue the overall development of the district. Under the local government system of Ghana, local authorities have been given the authority to plan, support productive activities, develop basic infrastructure, and act as the overall development agent of the district. Power has been devolved to DAs to enhance service delivery for local development, and since 1992 the government has channelled not less than $7.5 \%$ of annual national revenue to the Assemblies for development. With respect to planning, the District Medium Term Development Plan (DMTDP) is the primary instrument for development. These plans are required to identify all the potentials and development efforts at the local level whether they are sponsored by the assembly, central government, development partners and NGOs. Thus, DMTDP represent the development agenda of the district and all partners must refer to it. Clearly, DMTDPs are synonymous with LED plans.

In spite of this and the significance of LED, much attention has not been given to LED. For 
instance, ILO (2007) claims that, in Ghana, LED stems to a large extent from small, informal businesses. Their interests are hardly reflected in development strategies, however, leaving their potential for economic growth and poverty reduction untapped. Much in the same way, few studies have been conducted about LED in Ghana (Mensah, 2011; ILO, 2007; Offei-Aboagye, 2009; Mensah-Abrampah, 2004; Mahama, 2009). Many of these studies, however, suggest that despite the increasing recognition and promotion of decentralisation and local governance for LED in Ghana, local governments in many cases are too often unable to perform the tasks they have been delegated. Moreover, evaluations of the district assemblies' role as LED agency and their LED initiatives as well as their challenges rarely feature in most of these studies.

In contrast, this study draws on in-depth field investigation and analysis of the initiatives and challenges of LED in Ghana using the Atebubu-Amantin District. The main research questions are: What are the LED initiatives in the Atebubu-Amantin District. What are the challenges that the District face in implementing LED plans?

\section{Overview of Local Economic Development}

There is no single universal definition of the term "local economic development". In spite of this, attempts have been made by experts in the field of local and regional economic development to define the concept. For instance, Blakely (1994) defines LED as "a process by which local government and/or community-based groups manage their existing resources and enter into new partnership arrangements with the private sector, or with each other, to create new jobs and stimulate economic activity in a well-defined economic zone". Similarly, Coulson (1997) defines LED as "intervention to strengthen the local and regional economy." Broadly, LED represents a comprehensive strategy in which local actors and institutions try to make the best use of and harness local resources to conserve and create jobs as well as strengthen and promote business activity (Mensah, 2011).

According to Helmsing (2001), LED, consists of three strategies namely; Community Economic Development (CED), Locality Development (LD) and Enterprise Development (ED). In simple terms, Helmsing (2001) sees CED as the process by which local people build organizations and partnerships that interconnect profitable business with other interests and values. In this strategy more local people get involved, describing how the community should change and organizations look for ways to make their actions and investments reinforce the wishes and intentions of the whole community (Perry, 2003). The various strategies that are used in CED include women empowerment, training local businesses, and harnessing human capital through training. The overall aim of CED is to stimulate sense of belonging, promote self help and empowerment, contribute to the generation of (self) employment, improve living and working conditions in settlements, and to create public and community services (Helmsing, 2003).

Enterprise development focuses on the economic base of an area. The economic base in the view of Helmsing (2001) and Schmitz (1995) refers to those firms which are export geared where the destination of these exports could be other parts of the country or beyond national borders. These exporting firms normally cluster for several benefits such as support for 
each other, reduction in transaction costs as a result of close proximity to each other, lobbying for better training and education (Schmitz, 1998). This economic base can be enhanced by the promotion of small to medium enterprises by having in place connected services such as finance, transport and freight, and promoting industrial clusters (Helmisng, 2001).

It is said that, LED requires certain infrastructure, services and socio-economic capital for it to succeed which according to Helmsing (2003) is achieved through planning and putting in place the infrastructure as well as the capital. It is for this reason that Meyer-Stamer (2005) argued that LD is of a longer horizon than CED and enterprise promotion. He argued that LED involves a clash of cultures such as the culture of planners, who are long-term project thinkers and that of businesses, who think in very short periods. Meyer-Stamer (2005) noted that LD planning aims to maximize positive externalities of LED to reduce conflict, thereby enhancing attractiveness of an area such that LED goals such as poverty reduction are realized. However, LD as indicated by Helmsing (2003) and Meyer-Stamer (2005) has several components such as participatory LED, physical planning and development control, urban planning and design, infrastructure and socio economic overhead capital.

Amongst these strategies, LED assumes both supply and demand side policies. Supply side policies are directed towards businesses through tax incentives and non tax incentives which are either discretionary or non discretionary (Eberts, 2005)while demand side policies are aimed at providing an enabling environment for innovation, research and development to small and medium enterprises (SME's) development and entrepreneurial activity.

\subsection{Evolution of Local Economic Development}

Local Economic Development has been practiced for a while in wealthy countries such as the United States of America and the United Kingdom and relatively new in developing countries such as South Africa, Indonesia and others. Whereas the reasons attributed to the adoption of LED strategies in both developed and developing countries are many and varied, Nel (2001:1004) accredits this move to - "the so-called development impasse" the failure of earlier development approaches and the dubious results of structural adjustment programs. More specifically, Geddes (2004) notes that this came as a result of the direct slump in the economic growth of industrialized countries after World War II which placed a lot of pressure on governments, especially local governments, to become more innovative in trying to attract investment.

The Municipal Services Project (2001) relates the evolution of LED to the failure of traditional top-down planning policies and initiatives of government to achieve meaningful national development objectives leading to a shift in policy focus to target disadvantaged and underdeveloped areas. The intention of the policy shift according to the Municipal Services Project was to create favourable conditions such as subsidies and grants, aimed at luring investors to areas that were once deprived of direct investment and subsequent economic growth and development.

According to Geddes (2004), LED in the United Kingdom and the European Union became popular in the 1980s as a reaction to the rising problems of unemployment caused by economic restructuring and a fall in industrial activities. Geddes however, notes that during 
this period LED took the form of closer interaction and co-operation between local government, community-based groups, and trade unions. The rational was based on the notion that greater government and social interaction would promote sustainable job creation. This led to the establishment of co-operatives and community businesses, enterprise zones, urban development corporations, and enterprise councils alongside comprehensive training for community members in various disciplines of business and skills development (Geddes, 2004).

Dewar (1998) concurs that LED emerged in North America and particularly in the USA in the early 1970s as a response to a decline in economic growth, and also as a tool to stimulate it. These initiatives were especially directed at areas situated outside large cities and intervention programs initiated by government took the form of loans, grants and tax breaks.

To Nel (2001) experience of LED in African countries has the same evolutionary route as in the developed countries where the lack of external investment and declining economy necessitated an inward looking approach, but the African experience of LED is premised on the strategy of self-reliance. Similarly, Nel and Binns (1999) acknowledge that the importance of local control and empowerment, together with a reliance on local initiative and resourcefulness, are some of the key characteristics of LED initiatives in African countries. Within the developing world and Africa in particular, South Africa is often considered a leader or pioneer in terms of its planning interventions for LED (Rogerson, 2002).

Whereas LED between the two worlds (developed and developing) appears to be very similar, there are differences concerning the scale and focus. Nel and Binns (1999) indicated that LED in the developed world focuses on investment, big business support and large project development undertaken by relatively well resourced local agencies whereas that of developing countries often take the form of community-based initiatives, utilizing indigenous skills and seeking primarily to ensure survival, rather than participation in the global economy. Nel and Binns further argue that the reasons why the self-reliance approach adopted by many African countries proliferated as a means to stimulate local economic growth, was a basic response to the structural adjustment: debt crisis, drought, war, civil strife and the failure of top-down development schemes as experienced in these countries. These issues have forced many African countries to look at their own resources and skills to cope with the harsh realities of poverty and underdevelopment (Parker, 2004).

\subsection{Local Economic Development Programmes and Initiative}

The activities of LED that are designed to stimulate economic development at the local level are numerous and vary according to the types of support provided. The point here is that local authorities use a variety of tools in their LED work. Čapkova (2005) in explaining LED initiatives listed a lengthy menu of possible local initiatives and classified them into five broad categories: financial tools; property related tools; marketing; infrastructure development; and providing technical and information assistance. Čapkova was however quick to add that, this categorization is not rigid and the list could easily be broaden and subdivided according to the range of activities undertaken in diverse kinds of partnership. 
Similarly, Nel et al (2002) categorised LED interventions into five as follow; financial support; land and building development; information and marketing assistance; new planning and organisational structures; and training and employment. According to the World Bank (2002) LED interventions tend to have a focus on achieving set goals related to economic growth and empowerment. In order to achieve such goals, a fairly definable range of programmes are used. The most common programmes include: encouraging local business growth; support for new enterprises; improving the local investment climate; promotion of inward investment; provision of both hard and soft infrastructure; sector support for identified lead sectors; area targeting to address unique challenges; poverty reduction to ensure equity; and regeneration endeavours in areas subject to economic change.

The main components of LED programmes according to the Kpandai District Assembly (2010) include: Upgrading skills of Artisans; creation credit facilities; formation of business associations; and provision of adequate infrastructure to enhance trade. To add to the above, LED initiatives include: ensuring the functionality of local investment climate in order to boost local businesses, the encouragement of new enterprise, attracting outside investments, and investing in physical infrastructure. Human resource development and institutional support systems, supporting the growth of particular clusters of businesses, targeting certain disadvantaged groups and particular parts of the city for regeneration and supporting survivalist businesses should not be left out in the LED strategy (Pieterse, 2006).

Ofei-Aboagye (2009) is of the view that district assemblies have embarked on different programmes of LED. Such initiatives include micro-credit provision, agro-processing, infrastructural development, health and educational activities. Helmsing (2003), Cahill (2005) and Liou (2000) added that LED initiatives include situations where local authorities subsidise inputs, lower cost through tax incentives, promote research, encourage exports and target distressed areas for enterprise development.

Blakely (1994) comment on the provision of quality goods and services, specifically those of education opportunities as some LED activities and initiatives. In addition to this, LED strategies should incorporate the maintenance of existing services as well as the provision of new and improved services and infrastructure, which enable communities to meet their needs. Vaughan (1997) describes economic diversification and the introduction of new products as indications of a successful LED project. The economic success of an LED initiative is related to its ability to increase production (Stohr and Fraser 1981) through increased private sector investment and confidence as well as increasing the turn-over and investment made by local firms.

\subsection{Benefits and Challenges of Local Economic Development}

Local economic development has a number of benefits. The benefits of LED are linked to employment creation and therefore a platform for bringing "all hands on deck" in designing appropriate solutions to the unemployment problem. In the view of Gooneratne and Mbilinyi (1992) local initiatives constitute the only means of survival for the poor and disadvantaged thus local control of resources and initiatives is critical for economic development with great 
impact at the local level.

Similarly, evidence from rural Africa indicates that as part of the process of surviving, inhabitants of the world's poorest continent are becoming more reliant on indigenous technical knowledge, production systems and livelihoods ( $\mathrm{Nel}$ and Binns, 1999). Commenting on the benefits of LED in a World Bank report, Rodríguez-Pose and Tijmstra (2005) states that LED initiatives allow local people to adopt a more proactive stance with regards to their own future, even if they are living in areas of the world that have until recently, had little say or less control over the economic activities that take place in their territory.

Local economic development galvanizes the population towards a common objective and sense of purpose and stimulates citizens towards participation and entrepreneurial ventures, guarantees suitable conditions for sustainable employment, and promotes favourable environment for human development. As result Hill and Nel (2004) are of the view that, the aim of any LED initiative is to increase the number of jobs available to the various communities through the creation or encouragement of enterprise and business activity. To achieve this, it is important that local entrepreneurial resources are mobilised so that the jobs created can be occupied by the local, poorer communities (Blakely, 1994).

Another benefit of LED is that, it is consistent with the fight against poverty and social inclusion, assures environmental safety and leads to the reorientation of economic and social policies towards "bottom-up" development strategies (Canzanelli, 200; Helvetas and Anembom, 2005). Therefore, the active involvement of a variety of stakeholders not only helps to develop a stronger local civil society, but can also contribute to make local institutions more transparent and accountable.

In spite of its importance to development, LED faces a number challenges. One of the major challenges in promoting LED is integration of all LED partners. The UNDP (2003), points out that there is a lack of vertical and horizontal linkages between LED partners and other stakeholders which derails implementation and leads to duplication of activities. Furthermore, it is also a challenge to make all LED partners participate together with the citizenry (UNDP, 2003). The UNDP in an evaluation of LED projects in South Africa found out that the extent to which the local community shares in the definition of the LED problem and participates in its identification is a prime factor affecting project success.

The lack of resources and inadequate qualified personnel hamper LED particularly in poor resourced areas making implementation of LED difficult (UNDP, 2003). Smith (1998) is of the view that, local authorities often lack the appropriate apparatus or have differential capacities for providing an enabling environment for fostering partnership. Similarly, Taylor (1996) indicates that the performance of local firms may be hampered by inadequate administrative and technical know-how, difficulties in meeting deadlines and social pressures. Dere (2001) relates the challenges of LED to human hindrances such as attitudes to work, inadequate information systems, lack of systematic feedback and the absence of clear-cut responsibility. 
Another challenge is that most LED programmes lack poverty reduction targets, making it difficult to monitor and evaluate whether LED is reducing poverty (Nel et al., 2005). Thus the dynamics of poverty are scarcely explored in LED programs (Nadvi, 1999). Inadequate management control systems, at the local level could result in significant difficulties in the implementation of LED programmes (Ofei-Aboagye, 2009).

\section{Methodology}

This is a qualitative study using data from semi-structured individual interviews through purposive selection of officials from the Atebubu-Amantin District. Within the District, management who were involved in the formulation and implementation of district plans were involved in the study. With this in mind, the respondents for the study were the District Chief Executive (DCE), District Coordinating Director (DCD), Deputy District Coordinating Director (DDCD), District Planning Officer (DPO), Deputy District Planning Officer (DDPO), District Budget Officer (DBO) and Deputy District Budget Officer (DDBO). Others were District Finance Officer (DFO), Deputy District Finance Officer (DDFO), District Agriculture Officer (DAO), Deputy District Agriculture Officer (DDAO), Chairperson of the Development Sub-Committee (DSC), Business Advisory Center (BAC) Officer and the Presiding Member (PM). Purposive sampling was used in selecting the respondents for the study. In all fourteen participants were chosen but two of the respondents could not be interviewed, due to their absence at the time of the study.

During the interview, a tape recorder was used to record all responses. The study used content analysis to analyse the data. Content analysis is a procedure for the categorisation of verbal or behavioural data, for purposes of classification, summarisation and tabulation. The taped interviews were transcribed into word processor files. The transcripts were reviewed by the researcher for common themes and ideas of the study and the initial findings discussed with interviewees to ensure that summarised answers represent the views expressed. The final phase of the data analysis involved generating categories, themes and units for analysis.

\subsection{Profile of the Study Area}

This section of the study provides a brief description of the study area. The Atebubu-Amantin District is one of the twenty two (22) districts in the Brong-Ahafo Region. The District was known as the Atebubu District until the year 2004 when the Pru District was carved out of it. It is located between latitudes $7023^{\circ} \mathrm{N}$, and $8022^{\circ} \mathrm{N}$, and longitudes $0030^{\circ} \mathrm{W}$, and $1026^{\circ} \mathrm{W}$. It shares boundaries with Pru district to the North and Sene in the East both in the Brong Ahafo Region. To the South, it is bounded by three districts in the Ashanti Region namely Ejura-Sekyeredumase, Sekyere East and Sekyere West districts. The district capital, Atebubu, is about $155 \mathrm{~km}$ from Kumasi and $158 \mathrm{~km}$ from the Regional capital. The district covers a land area of $1996 \mathrm{~km} 2$ Pru District has a land size of 2,195km2. According to the 2010 Population and Housing Census (PHC), Atebubu-Amantin District has a population of 105,938. The distribution shows that females account for 52,264 of the number with 53,674, males.

Most of the non-Akan tribes represent various ethnic groups such as Mamprusis, Dagaaba's, Frafra's, Kusasi's Moshi's and Gonja's. In terms of religion, the district is dominated by 
Christians who are $62.2 \%$, followed by Muslims $29.6 \%$ while the remaining $8.2 \%$ practice traditional religion. The spatial pattern of settlements in the district could be described as dispersed with exception of a few settlements located along the major Atebubu-Yeji road. There are only two urban settlements in the district namely, Atebubu and Amantin, through which one of the subsidiary highway is the only tarred road within the district. Agriculture is the mainstay of the Atebubu-Amantin district economy. It employs about $70 \%$ of the economically active labour force. Nearly every household in the district is engaged in farming or agriculture related activity.

\section{Key Findings of the Study}

\subsection{Local Economic Development Initiatives in the Atebubu-Amantin District}

All the interviewees were unanimous that, the District does not have a specific LED policy. They however agree that, it is the mandate of the district to embark on economic development. As noted by the DCD: "the district has the mandate and the legal backing to get involved in LED. The local government gives us the backing for the overall development of the district and LED is part of this". In the view of the DPO, the mandate of district assemblies is broad with many functions. He states "we have the right to embark on LED as long as it does not conflict with any legal provision in Ghana. Even though, we do not have a LED policy, I think LED falls within our MTDP because this is the overall development policy or strategy of the district". Similarly, the Chairman of DSC indicated that, the district does not have a LED policy. He was however optimistic that, it is the mandate of the District to embark on economic development using the potentials of the District. He comments "as the Chairman of the DSC, our role is to identify potentials, opportunities and constraints of the district for economic and I think that is LED".

The above statements are clear that, the Atebubu-Amantin district has the mandate to embark on economic development. Therefore, without a specific LED policy, the District has implemented specific programmes and initiatives which are considered as pro-LED. Agriculture is one of the areas that have been widely explored by the districts as a LED activity. With respect to this, the DPO states that:

"the survival of the majority of the people is largely dependent on farm related activities. Our attention to increase agricultural development as a local development tool rests on the assumption that increased agricultural production will increase rural incomes, which in turn, will increase the people's ability to access basic social services".

Having recognised the importance of agriculture, the District sponsored a program which was facilitated by the veterinary department where two hundred (148 males and 52 females) livestock farmers were trained on disease identification and control. The DDAO indicated that a lot of people have cultivated Teak and that the directorate is yet to introduce them into other profitable plantations like Mango, Palm nut, and Moringa.

In pursuance of the agricultural agenda, the DAO states that "this is an agric area and we are committed to developing it. Therefore we have provided direct agricultural infrastructure like the construction of sixty five vegetable solar dryers at key vegetable production centers, three improved rice milling machines to the famers, rehabilitation of the silos at Tuse, and the 
construction of two dug-out irrigation facilities at Watro and New Konkrompe for dry season farming". Farmers have been assisted to obtain viable seeds, seedlings and breeds of livestock from the District Agric Office. The DDAO added that "we did not only give them the seedlings, we also provided them with advisory services on farm management techniques and application of modern farming techniques and ask them to call on us anytime they need advise".

With respect to agro-processing as part of the agricultural strategy for LED, small-scale agro-processing technology is often used. This is particularly suitable for women as is built on indigenous knowledge that requires few inputs, and can be carried out in the home, thus enabling women to fully participate while maintaining their various other roles as career women and homemakers. Through this women have trained on how to process cassava into Gari, flour, and Starch. Other agro-processing equipment provided includes a local technology use to pill corn and corn mills. The aim of doing this is revealed by the DAO as "we want to empower these women and make them employable and economically viable".

Another significant area that has been used by the District for LED is infrastructural development. The DCE made it clear that "infrastructure is the starting for the development of any locality and therefore we are vigorously undertaking major infrastructural development". The interviews reveal that the infrastructural services that were undertaken as part of their LED initiative include the construction and maintenance of feeder roads, clinics, provision of potable water, electrification, and markets. The DDPO reveal that, electricity has been expanded to eighteen communities under the Self Help Electrification Project Four (SHEP-4). Several roads have been constructed and rehabilitated. Some of the roads that have been constructed include Nyomoase to Trowhe-Kotope $(7.5 \mathrm{~km})$, Issifu Akura to Mansano $(19 \mathrm{~km})$, Akokoa to Abdulai Ntow $(14.5 \mathrm{~km})$, Mem to Yaw Braso $(13.8 \mathrm{~km})$ and Sampa to Pruso No.1 (10.35km).

Good road networks often have positive effect on the livelihood of the rural population because it leads to accessing market centers and other communities, especially during the rainy season. This makes access to inputs, markets, health care and educational facilities to rural areas easy. Majority of these feeder roads link foods producing areas and marketing centres. By extension it is expected that the rehabilitation and construction of the $65.15 \mathrm{~km}$ feeder roads should lead to the improvement in the lives of the beneficiary communities.

In relation to human resources development as a LED strategy, the key interviews revealed that many residents have been trained on various areas of their livelihood. For instance, one hundred and fifty people have been trained in grass cutter rearing, fifty SMEs have been trained on various programs of business management, three hundred people have been trained in modern techniques of storing maize and two hundred farmers have been trained on the application of fertilizer and organic manure. The BAC Officer hinted that, the BAC has provided training on Batik, tie and dye to thirty people. It has also provided series of training to seventy five people in soap making. The aim of this has been stated by the BAC Officer as follows:

"these training programmes are very important as they can turn the lives of redundant 
individuals around by empowering them to engage in profitable economic ventures. They are also seen as a way of encouraging and strengthening entrepreneurship in the district".

Employable skills have been provided for the youth in productive economic ventures. These skills include how to start and manage SMEs and available and possible sources of funding. The BAC Officer indicated that, the Ministry of Women and Children Affairs have supported the district to train one hundred women on income generating activities. Forty physically challenged people were trained on various vocational skills. Thirty livestock farmers were trained on the identification and treatment of diseases while fifty farmers were trained on integrated pest management. The DDAO emphasised that "the aim is to develop the technical competences of the farmers in modern farming practices such as the management and use of irrigation facilities, manure and fertiliser application".

The Atebubu-Amantin District has also developed tourism as a LED strategy. As a result, the Assembly documented tourist sites in their Medium Term Development Plan (2006-2009) and most of these tourist sites have been rehabilitated to create employment. Some of these sites are the tortoise shrine at Duabone and the magical bell which is located in Atebubu town. The significance and importance of these sites to LED is captured in this statement by the DPO as:

"to the best of my knowledge, there is no tortoise tourist site in Ghana and this makes it unique and a very big opportunity for Duabone to attract thousands of tourists to the area. This can create employment opportunity for the people by developing it and making tourists aware of such interesting animals".

Again, micro financing has been used by the District as a LED strategy. Credit facilities have been provided to farmers, entrepreneurs, individuals and SMEs to boost their production capacity. Financial assistance has been extended to twenty five distressed SMEs. Similarly, start up capital has been provided for graduate trainees to start businesses after they have graduated from various training programmes. The BAC Officer indicated that his office has disbursed an amount of GHC 27, 310 to twelve groups and one hundred and twenty seven SMEs. To him "this has lead to the expansion of businesses in the district". He added that "along with infrastructure and policies relating to serving the poor, micro credit has become more popular in developing countries to attack poverty". Micro-Finance and Small Loans Center (MASLOC) is popular in providing financial assistance at the district level. However, as at the time of collecting this data, MASLOC just opened it office at the district, hence no data from MASLOC.

\subsection{Challenges of Local Economic Development in the Atebubu-Amantin District}

From the findings above, there is no doubt that the district has harnessed economic activities in the area through LED. However, District has encountered a lot of challenges. The respondents indicated that the progress of the agricultural sector has been hampered by the absence of farm-to-market roads, the low use of technology, poor rural infrastructure, poor marketing channels, non-availability of resources, and so on. 
It was found that there are not enough agriculture extension officers to assist the farmers and give them technical advice on crop production, preparation, pest and disease control, soil conservation and other areas. This is illustrated by this statement from the DDAO "there are only six agricultural extension officers who attend to about 7365 farmers, spread over fifty-five extension operational areas. This situation is compounded by the lack of motorbikes that hinder their mobility to most parts of the district". Still relating to agriculture, there is inadequate irrigation development, insufficient, and inadequate storage facilities, and high cost of transporting foodstuffs to the market.

Another challenge that they enumerated was poor infrastructure. Infrastructure is basic in promoting economic activities. Though these facilities are important for development, the District is faced with inadequate financial resources to be able to expand and improve upon the infrastructure such as roads and market facilities due to the demand on its resources by other forms of developmental activities. Narrating the infrastructural challenges of the district, the DFO state that "the district does not have the necessary financial capacity to be able to re-gravel and re-shape all the feeder roads all the time because our main source of funding is the District Assemblies Common Fund (DACF) which does not even come on time". This has a lot of consequences. As the DPO noted "some rural communities are normally cut off from the rest of the district during heavy rainy season due to the poor nature of their roads. This increases the cost of transportation during this season. Farmers lose income as they are not able to cart their produce to the marketing centres for sale".

One of the significant challenges that was revealed during the interview was lack of collaboration. The interaction and partnership among actors is key in the LED process. However, the DPO indicated that: "there is little interaction and cooperation among internal actors. The DAO also confirms this as "there is lack of formal networks which are able to guide the development process". The point that is been put across here is that, there are several NGOs, CBOs, FBOs and other donor support projects in the districts, but there is lack of collaboration leading to duplication of programmes and efforts.

Another challenge that was discovered was inadequate capacity of local actors. The respondents noted that some of the personnel of the district assemblies lack the technical competence to undertake a comprehensive LED strategy targeted at the poor. The DDCD states "my experience shows that some of the personnel at the district level are not up to the task and lack the managerial and technical ability to forecast the future and plan". It was therefore not surprising that none of the development partners has a formal LED strategy.

The respondents further cited finance as a challenge. They explained that because of inadequate finance they are not able to provide huge sums of money to their target groups and that the monies they give to them are sometimes small for any huge investment. The BAC Officer added that "even sometimes, we find it difficult to support prospective beneficiaries who have been trained in business management and book keeping". It was also found that non payment of loans is a threat to their survival. This point is illustrated here by the BAC Officer: "since the beginning of the loan administration, it has been noted that some groups have still not paid their first loans-they still owe, some loans are overdue for as long as eight years with their interest more than double the principal". This issue of finance also 
affect farmers. The DDAO comments:

As a result of inadequate financial assistance for the farmers, they are not able to buy good seedlings, fertilizer, chemicals and pesticides; afford tractor services, and others. The ultimate effect is that they are unable to expand their farms and engage in commercial or large-scale agriculture because they use their own labour or family labour, crude and natural method of farming leading to low yields and their situation continue to worsen.

Also among the challenges is lack of LED policy. Though some aspects of LED are captured in the DMTP which is the broad development strategy of the district, the constitution and the local government Act, it does not measure up to the standard of a LED policy. This is because DMTP overlook at the basics and other needs of LED and in actual fact it does not put major emphasis on LED. Also in spite of the mandate to promote LED, the legal framework failed to state how this was to be done. It does not also make it obligatory for the district to go into it. This has the ability of leaving the district to decide what it should do in the area of LED. This may not auger well for the active and effective involvement of the district LED. The DPO asserts that "we need a framework or policy in this direction and this will provide for the needed human and financial resources".

\section{Discussion of Findings}

The first objective of this study was to look at LED programmes and initiatives. The study reveals that, one of the LED initiatives is agriculture. In fact using agriculture as a LED strategy is beneficial considering the context of this study and as noted by Fraser (2009), agriculture remains vital to growth and poverty reduction in rural areas. Agriculture has a lot of potentials to reduce the poverty of people in rural areas and should be improved and given the necessary attention. Increase in agricultural development as a local development tool rests on the assumption that increased agricultural production will increase rural incomes, which in turn, will increase the people's ability to access basic social services. This, it can be argued, is similar to the views of Christianson and Demery (2007) that, an African development strategy that is firmly grounded in agricultural and rural development can result in a more sustained impact on poverty.

The study found that the District embarked on infrastructure programs such as roads, markets, electricity among others as LED initiatives. The implication of these infrastructure investments and development is that they can lead to higher farm and non-farm productivity, employment and income. The finding of this study is related to that of Čapkova (2005); World Bank (2002); Kpandai District Assembly (2010) and Blakely (1994). All these studies identified the importance of infrastructure in LED strategy and initiatives. Extension of electricity to rural areas for example has been acknowledged by Electricite de France [EdF] (2002) to result in an increase in the human development index. Thus, investment in infrastructure is important to establish the conditions necessary for the development of the rural economy and to improve human development. It is therefore important that much of these infrastructure focus on issues relating to the potentials of the area especially irrigation, farm related machinery and small processing equipment which are likely to have direct impact on the local residents. 
Another LED program that the District has embarked on is Human Resource Development (HRD). Similarly, this is related to the findings of Capkova (2005); World Bank (2002); Kpandai District Assembly (2010); (Pieterse, 2006) and Blakely (1994). The aim for undertaking a HRD is to develop the technical competences of the farmers in modern farming practices such as the management and use of irrigation facilities, manure and fertiliser application, and that of entrepreneurs in conceptual and managerial aspects of business. Human resources are the most valuable assets of any organization.

Training encompasses the broad set of activities that improve the performance of the individual in whatever economic activity they are engaged in. For example, training has the potential to: provide the skills, knowledge, and aptitudes necessary to undertake required job efficiently, increase efficiency by reducing spoilt work, misuse of machines, and lessening physical risks. Training and development will not only help the beneficiaries to be efficient but also help them to identify new opportunities in their locality.

Financial assistance is vigorously been pursued by the District as a LED strategy. This is clearly related to the findings of $\mathrm{Nel}$ et al (2002); Ćapkova (2005); Kpandai District Assembly (2010). Finance is important in whatever business one is into. As a result, the former UN Secretary, Kofi Annan espouses that sustainable access to microfinance helps reduce poverty by generating income, creating jobs, allowing children to go to school, enabling families to obtain healthcare, and empowering people to make the choices that best serve their needs. In short, along with infrastructure and policies relating to serving the poor, micro credit has become more popular in developing countries to reducing poverty and job creation (UN International Year of Microcredit, 2005).

The second objective of this study is to find out the challenges of LED. A number of challenges that confront LED in the District are lack of finance, inadequate agricultural assistance, poor road network and other infrastructure and market accessibility. Also among the challenges is inadequate technical and human resource competence to provide the required skills in order to customise the training to suit the needs of their beneficiaries. Other challenges include ineffective coordination among the District and development partners, improper targeting of beneficiaries and lack of capacity to monitor and evaluate the impact of their programs. These findings are related to a number of studies in the literature. For instance, the UNDP (2003) has pointed out that there is a lack of vertical and horizontal linkages between LED partners and other stakeholders as well as difficulty in getting all partners to participate. Issues of finance, lack of capacity, infrastructure among others have been raised by a number of studies (Blakelyand Bradshaw, 2002; UNDP, 2003; Nel et al, 2005; World Bank, 2002; Nadvi, 1999).

With respect to funding for agriculture, IFAD (2001) indicates that most developing countries have experienced a significant reduction in funding for rural agriculture. If this trend is not reversed it will be very difficult for rural areas to escape the poverty trap. As IFAD (2001) points out, the declining financial support for agriculture is extremely damaging for rural development and poverty reduction efforts. 


\section{The Way Forward}

Based on the findings of the study, the way forward for LED is recommended as follows; there is the need for a LED department and policy. It is clear from the findings that the district does not have in place a LED strategy and department. It is therefore important that a comprehensive LED strategy be put in place. This department will develop the strategy, facilitate and coordinate all LED activities in the district. It should include representatives from all the key departments, sub-committees, technical staff of the district, representatives from major business associations and economic entities and local leaders. Finally, the local government should give this unit the needed support in terms of resources for its activities.

Attention should also be paid to finance. It was discovered from the study that finance is a challenge to LED. The District should enter into partnerships with other stakeholders in the process where the financial burden on it can be shared with these. It should develop a good working relationship with the local rural banks, especially the Credit Union, Amantin Kasai and YAPRA Rural Banks and encourage them to assist local economic entities with financial resources. It should also find solutions to the loop holes in its local revenue mobilisation. Financing programs should be targeted at businesses whose behaviour is likely to be affected, such as businesses with good alternative locations, or businesses unlikely to receive normal bank financing.

The study found that there is inadequate collaboration, integration and partnership between the District and other stakeholders. Therefore it is recommended that, the district should value all stakeholders in the LED process, improve the level of stakeholder involvement in the process, create a stakeholders' forum and develop a stakeholder involvement framework. Drawing a LED policy is not an easy task, it requires collaborative effort by all. In a nutshell, all the stakeholders should collaborate to come out with a comprehensive LED policy for the district. This will help the district to utilise some of their resources in terms of human and financial together so that there would not be duplication of programs.

In view of the findings that the local government has inadequate capacity in terms of technical know-how, it is recommended for the recruitment and strengthening of the capacity of the staff of the district to be able to come out with and manage LED activities. This is because the task of LED needs qualified and professional individuals who can apply their experience to come out with development. There is the need for a strong capacity of all forms for LED drive. This will help it plan for and implement LED in the district. Again, it should re-orient its staff whose activities are likely to have a bearing on LED on the ideals and principles of the concept. Training must also be orgainse for the staff in relation to LED planning, implementation, financing and management as it will improve upon their capacity and to ensure the effectiveness of the district in this direction.

The authorities must make the marketing of the district and its potentials a prime focus. It could employ the services of marketing professionals to help advertise the district to the general public, would-be investors and the entire world. It ought to adopt pragmatic steps such as making good use of the district website to make known its offers and the available potential of the district to the outside world. It should also strengthen its business attraction 
strategies so as to attract more and vibrant economic entities and activities into the district to feel the gaps that it cannot fulfil on its own.

\section{Conclusion}

Local Economic Development is generally a strategy to promote economic opportunities and growth at the local level by addressing constraints and improving the overall business environment to encourage entrepreneurial behaviour and investments. The interventions to promote LED can therefore take various forms and its scope depends largely on the context in which it is been undertaken. This paper has looked at LED initiatives and their challenges in the Atebubu-Amantin District. A number of LED initiatives have been implemented in these districts and these initiatives have encountered a number of challenges. It is crucial to note that LED is an important stimulus for local economies and can be an effective tool in accelerating progress towards poverty reduction and achievement of MDGs locally. In a country like Ghana, LED can minimize disparities and assist districts and regions to reduce economic gaps with richer districts and regions in the country. This is because LED initiatives will directly benefit the locals and their businesses to optimize their potentials, and improve their incomes. Therefore, any LED initiatives should try to minimize the challenges that will arise in other to maximize its potentials.

\section{References}

Adebayo A.E and Taibat O. L (2006) Dynamics of Poverty Alleviation and Local Economic Development in Nigeria: Physical Planning Perspectives. Akure, Nigeria, Federal University of Technology.

Atebubu-Amantin District Assembly (2008). District Medium Term Development Plan. Unpublished: Atebubu.

Blakely, E. (1994). Planning Local Economic Development. Newbury Park, CA: Sage.

Blakely, E.J. and Bradshaw T.K. (2002). Planning Local Economic Development-Theory and Practice. Thousand Oaks: Sage.

Cahill A. (2005). Engaging Communities for Local Economic Development: Lessons from the Philippines. Department of Human Geography, Research School of Pacific and Asian Studies, Australia: Australian National University.

Canzanelli, G. (2001). Overview and Learned Lessons on Local Economic Development: Human Development and Decent Work. ILO and Universities Working Paper, Geneva.

Christiaensen, L. and Demery L. (2007). Down to Earth: Agriculture and Poverty Reduction in Africa. Washington DC: World Bank.

Čapkova S. (ed) (2005). Local Government and Economic Development. In Local Government and Public Service Reform Initiative. Budapest and the Department of International Development Publication.

Coulson, Andrew. 1997. Local Economic Development: A Guide to Practice. An INLOGOV 
Discussion Paper. Birmingham: Birmingham University.

Dere C. (2001). The Role of Local Government in Economic Development: the case of Tema Municipal Assembly. Dissertation Submitted in Partial Fulfilment of the Requirements for the Masters of Business Administration Degree, Maastricht School of Management, Netherlands.

Dewar, M.E. (1998). Why State And Local Economic Development Programs Cause So Little Economic Development. Economic Development Quarterly. Vol. 12 (68):87.

Davis J. and Catherine R. (2005). Addressing Poverty through Local Economic and Enterprise Development: A Review of Conceptual Approaches and Practice. Working paper 3. Chatham, Natural Resources Institute.

Eberts, R. (2005). Overview of State and Local Economic Development Policies and Practice in the United States. http://www.jil.go.jp/events. accessed on 10/09/2010

Electricite de France [EdF] (2002). Electricity for all: Targets, Timetables, Instruments", Prepared as a contribution to the World Summit on Sustainable Development. Electricite de France, Paris

Fraser A. (2009). Harnessing Agriculture for Development. Oxfam International Research Report. Teresa Cavero: Oxfam International

Geddes, M. (2004). Linking Local Economic Development to Anti-Poverty Strategies: Experiences in the United Kingdom and the European Union. www.local.gov.za/ DCD /ledsummary/ledo5 accessed on 11/10/2010.

Gooneratne, W. and Mbilinyi, M. (1992). Reviving Local Self-Reliance. Nagoya: United Nations Centre for Regional Development.

Helmsing, A .J.H (2003). - Local Economic Development: New Generators of Actors, Policies and Instruments for Africa" in Public Administration and Development. No 23, pp.67-76

Helmsing, A. J. H. (2001). Partnerships, Meso-institutions and Learning. New Local and Regional Economic Development Initiatives in Latin America. The Hague: Institute of Social Studies (mimeo).

Helvetas C. and Anembom C. (2005). Handbook on Local Economic Development: Guidelines and Training Program for Service Providers. http://www.helvetascameroon. org/Cameroon/global/pdf/program/tools/LED\%20Handbook.pdf, (Accessed on September 22, 2010).

Hill, T.R. and Nel, E.T., (2004) Thoughts of Rural Development Researchers in South Africa. In: Fincham, R., Georg, S. and Nielsen, E.H. (eds.) Sustainable Development and the University: New strategies for research, teaching and practice. Brevitass CC, South Africa, 129-159

International Fund for Agricultural Development [IFAD] (2001). Rural Poverty Report 2001. The Challenge of Ending Rural Poverty. Oxford: Oxford University Press.

International Labour Organisation [ILO] (2007). Local Economic Development in Ghana: 
Rooting Public-Private Dialogue. ILO - Ghana Decent Work Pilot Program Office; Accra, Ghana.

Kpandai District Assembly (2010). Strategic environmental assessment report on the 2010-2013 medium Term development plan activities

Liou, K. T. (2000). Symposium on Local Economic Development Financing: Issues and Findings. Journal of Public Budgeting, Accounting and Financial Management. Fort Lauderdale, USA

Mahama C. (2009). Local Economic Development and Local Government in Ghana: Navigating a Viable Path to Reform. Vol. 1 (1): 29-53

Mensah-Abrampah, K. (2004). Local Economic Development in Ghana: the Social Investment Fund Experience. Paper Presented at Decent Work/Local Economic and Social Development Restitution Workshop organised by ILO Training Center/Ghana. Decent Work Pilot Programme/Institute of Local Government Studies. August, 2004. Accra

Mensah, J.K (2011). Poverty Reduction through Local Economic Development in the Pru and Atebubu-Amantin Districts in Ghana. Dissertation Submitted in Partial Fulfilment of the Requirements for the Master of Philosophy in Public Administration Degree, School of Graduate Studies, University of Ghana.

Meyer -Stamer J, (2005). The Hexagon of LED. Meso-partner Working Papers No. 3. Duisburg.

Municipal Services Project (2001). Local Economic Development Debates in South Africa. Occasional Paper No. 6. Cape Town: Municipal Services Project.

Nadvi, K. (1999). Collective Efficiency and Collective Failure: The Response of the Sialkot Surgical Instrument Cluster to Global Quality Pressures. World Development Special Issue on Industrial Clusters in Developing Countries. Vol. 27(9):1605-1626.

Nel, E. L. (2001). Local Economic Development: A Review and Assessment of its Current Status in South Africa. Urban Studies. Vol. 38(7):1003-1024.

Nel, E. L. and Binns T. (1999). Beyond the Development Impasse: The Role of Local Economic Development and Community Self-Reliance in Rural South Africa. Journal of Modern African Studies. Vol. 37(3):389-408.

Nel, E.L., Hill, T.R. and Eising, W., 2002: Evaluation of local economic development in Cato Manor, Unpublished report for the Cato Manor Development Association, Durban.

Offei-Aboagye, E. O. (2009). Economic Decentralisation and Local Development: Concepts and Issues. Journal of Local Government Studies. Vol. 1 (1): 1-28

Parker G. D. (2004). The challenge of Sustainable Land-based Local Economic Development in Poor Communities of South Africa: The Case of Groblershoop, Northern Cape. A thesis for Masters Philosophy in Public Administration. University of Kwazulu-Natal (Unpublished).

Perry M. (2003). Economic Relations in European and Southeast Asian Borderlands: 
Comparing Trans-State and Inter-State Experiences. Paris: Presses de.

Pieterse, E. (2006). A Framework to Link Local Economic Development to Anti-Poverty Strategies. http://www.dplg.gov.za. Retrieved December 19, 2010

Rodríguez-Pose A. and Tijmstra S. (2005). Local Economic Development as an alternative approach to economic development in Sub-Saharan Africa: A Report for the World Bank. Houghton, London.

Rogerson, C.M. (2002). Planning Local Economic Development: Policy Challenges from the South African experience. Africa Insight. Vol. 32 (2):39-45.

Schmitz, H (1998). Responding to Global Competitive Pressure: Local Cooperation and Upgrading in the Sinoz Valley Brazil. IDS Working Paper No. 82, IDS, Brithgon.

Schmitz, H (1995). Collective Efficiency: Growth Path for Small Scale Industry. Journal of Development Studies. Vol. 31(4):11.

Smith B. C. (1998). Local Government and the Transition to Democracy. In Public Administration and Development.Vol. 21 (1): 53-64

Stohr, W. and Fraser T. (1981). Development from Above or Below? The Dialectics of Regional Planning in Developing Countries. Wiley, London

Taylor, D.R.F. (1992) Development from within and survival in Rural Africa: A synthesis of theory and practise. In: Taylor, D.R.F and Mackenzie, F. (eds) Development from within: Survival in rural Africa. Routledge, 214-258

United Nation Development Program (2003). South Africa Human Development Report: The Challenges of Sustainable Development in South Africa, Unlocking Peoples Creativity. Cape Town: Oxford University Press.

United Nations International Year of Microcredit (2005). http://www.yearofmicrocredit.org July 2005.

Vaughan, A. (1997) An Integrated Rural Development Strategy for KwaZulu-Natal: Towards the formulation of an effective policy. Transformation, 33:34 - 57

World Bank (2003). Local economic development A Primer: Developing and Implementing local economic development Strategies and Action Plans. Washington DC: World Bank.

World Bank (2002) Defining Local Economic Development Premier. World Bank Urban Development Division. December, 2002 